\title{
Experimental evidence for the adaptive response of aquatic invertebrates to chronic predation risk
}

\author{
Łukasz Jermacz $^{1,2}$ (D) Anna Nowakowska ${ }^{3} \cdot$ Hanna Kletkiewicz $^{3} \cdot$ Jarosław Kobak $^{1}$
}

Received: 6 September 2018 / Accepted: 2 January 2020 / Published online: 9 January 2020

(c) The Author(s) 2020

\begin{abstract}
As acute stress induced by predation risk can generate significant oxidative damage, prey organisms are forced to balance their defence reaction and the cost of activating the cellular defence system. Stress tolerance differs significantly among species; therefore predator pressure indirectly shapes the community structure. To test adaptation abilities of amphipod crustaceans (Dikerogammarus villosus and Gammarus jazdzewskii) we exposed them to acute (35 min.) and chronic (1 or 7 days) predation risk (the Eurasian perch). We measured respiration (related to metabolic rate), cellular defence systems (antioxidant enzyme (catalase) activity and heat shock protein (Hsp70) concentration), and the level of oxidative damage (thiobarbituric acid reactive substances (TBARS) concentration). Both amphipods increased their respiration rate in the presence of predation cues, irrespective of the duration of their pre-exposure to danger. This increase in D. villosus was initiated more quickly (immediately vs. after $10 \mathrm{~min}$. of the test) and lasted for a longer time (20 vs. $10 \mathrm{~min}$.) than in $G$. jazdzewskii. However, only G. jazdzewskii after a short exposure to predation risk exhibited an increase in its catalase activity, Hsp70 concentration and oxidative damage. No changes in these parameters were exhibited by $D$. villosus or after a chronic exposure of G. jazdzewskii to predation cues. Our results show that prey organisms are able to reconfigure their physiology to maintain increased metabolic rate under prolonged predator pressure and, at the same time, reduce oxidative damage as well as costs related to anti-oxidant defence.
\end{abstract}

Keywords Fear effects $\cdot$ Stress physiology $\cdot$ Antioxidant defence $\cdot$ Non-consumptive effects $\cdot$ Fight-or-flight response

Communicated by Donovan P. German.

Electronic supplementary material The online version of this article (https://doi.org/10.1007/s00442-020-04594-z) contains supplementary material, which is available to authorized users.

Łukasz Jermacz

jermacz@umk.pl

1 Department of Invertebrate Zoology, Faculty of Biology and Environmental Protection, Nicolaus Copernicus University, Lwowska 1, 87-100 Toruń, Poland

2 Department of Ecology and Biogeography, Faculty of Biology and Environmental Protection, Nicolaus Copernicus University, Lwowska 1, 87-100 Toruń, Poland

3 Department of Animal Physiology, Faculty of Biology and Environmental Protection, Nicolaus Copernicus University, Lwowska 1, 87-100 Toruń, Poland

\section{Introduction}

Predator pressure is a crucial evolutionary force, driving a number of adaptations in prey species (Yoshida et al. 2003; Bollache et al. 2006; Engel and Tollrian 2009; Naddafi and Rudstam 2013). In response to predation risk, prey individuals reallocate available energy from growth and reproduction to defence mechanisms, expressed as changes in behaviour, morphology and life history (Creel et al. 2007; Strobbe et al. 2010; Hawlena et al. 2011). Moreover, at the same time prey individuals limit food acquisition, thus intensifying negative non-consumptive predator effects (Jermacz and Kobak 2017; Beermann et al. 2018). Therefore, at a demographic scale, the costs of indirect predator effects are comparable with those resulting from direct predation (Werner and Peacor 2003; Preisser et al. 2005; Zanette et al. 2014; Sheriff et al. 2015), significantly affecting prey mortality (McCauley et al. 2011; Siepielski et al. 2014). Indirect predator effects are strongly associated with prey growth reduction due to modification of feeding behaviour (Werner and Anholt 1993; 
Jemacz et al. 2017c; Beermann et al. 2018). However, it was experimentally demonstrated that changes in prey physiology could also be responsible for the lower growth (Slos and Stoks 2008; Hawlena and Schmitz 2010; Janssens and Stoks 2013; Jermacz and Kobak 2017) or even death (McCauley et al. 2011) of prey under predation risk.

In the first step after detection of the predator presence, many prey species increase their metabolism rate and relocate resources to improve their vigilance and capability of a fast response (Hawlena and Schmitz 2010). Such adaptations increase the efficiency of an organism, necessary during a defence reaction (Sapolsky 2002). However, the duration of this maximum efficiency period is limited due to the destructive effect of prolonged and increased reactive oxygen species (ROS) synthesis (Monaghan et al. 2009). To reduce the negative effect of ROS activity, prey species are forced to activate cellular defence systems including anti-oxidant enzymes and heat shock proteins. On the one hand, activation of the cellular defence system is energetically costly (Sørensen et al. 2003; De Block and Stoks 2008) and in consequence the prey organism allocates less energy to other activities. On the other hand, non-neutralized ROS generate damage in key biological molecules such as DNA, proteins and lipids (Monaghan et al. 2009) significantly affecting organism functionality. Therefore, chronic predation risk may cause a number of negative changes in prey physiology and/or behaviour and, in consequence, affect its survival (Hawlena and Schmitz 2010; Janssens and Stoks 2014).

A number of compensatory mechanisms limiting negative physiological consequences of defence reactions exist (Thaler et al. 2012; Dalton and Flecker 2014; Van Dievel et al. 2016). However, their effectiveness varies among prey species (Benard 2004). For example the tobacco hornworm, Manduca sexta, increase food assimilation to balance the lower consumption rate under predation risk, but the duration of the increased assimilation is limited and related to the alteration of body composition (Thaler et al. 2012). Therefore, in communities with high predator pressure, the difference among species in resistance to negative effects of chronic predation risk may affect species fitness and, in consequence, community composition (Jermacz and Kobak 2017).

Nevertheless, there are still gaps in our knowledge of the ability of prey to function under prolonged predation risk, especially in the context of metabolic rate. Most of the studies report results of only short or only prolonged prey exposure to predation risk, which do not allow time-related modifications of their physiology to be observed. Here we present one of the first studies focused on the abilities of aquatic invertebrates to deal with prolonged predation risk, using metabolic rate, anti-oxidant defence and level of oxidative damage as markers of adaptations to the predation risk. As a model, we used two freshwater amphipod species
Dikerogammarus villosus and Gammarus jazdzewskii, recently distinguished from G. fossarum complex (Rudolph et al. 2018), exposed to short and chronic predation risk generated by kairomones of the Eurasian perch Perca fluviatilis. The former species is invasive in many parts of Europe, relatively large, less active and armoured with a harder exoskeleton compared to non-invasive, smaller G. jazdzewskii (Rewicz et al. 2015; Błońska et al. 2015).

We hypothesized that under acute predation risk prey organisms would increase their metabolic rate to maximize the efficiency of their defence reaction. Moreover, we predicted that in consequence of the higher metabolic rate prey organisms would activate their cellular defence systems. As the increased metabolic rate generates significant costs due to the activation of the anti-oxidant system, we assumed two scenarios of physiological modifications after prolonged predator pressure. In the first scenario, prey organisms would reduce their metabolic rate to avoid oxidative damage as well as costs related to the cellular defence mechanism. In the second scenario, prey organisms would keep their metabolic rate at the increased level and suffer oxidative damage due to exceeding the efficiency of their cellular defence system.

\section{Material and methods}

\section{Animal collecting and housing}

Individuals of $D$. villosus were collected from the nearshore zone of the Włocławek Reservoir (a dam reservoir on the lower River Vistula, Central Poland, N:52 37'03", E:19 $\left.19^{\prime} 37^{\prime \prime}\right)$ using traps made of artificial Christmas tree branches. Individuals of G. jazdzewskii were captured in the Zielona Struga Canal (a left tributary of the River Vistula, $\left.\mathrm{N}: 53^{\circ} 00^{\prime} 12^{\prime \prime}, \mathrm{E}: 18^{\circ} 27^{\prime} 39^{\prime \prime}\right)$ with a hand net. As predators we used the Eurasian perch (Perca fluviatilis), which coexists with both gammarid species in their native and invaded ranges (Kottelat and Freyhof 2007, personal observation). Fish were caught by electrofishing (device type EFGI 650, BSE Bretschneider Spezialelektronik, Germany) from the Włocławek Reservoir (the same place as the location of gammarid collection). Collected perch and gammarids were transported in 20-L containers to the laboratory and placed in 200-L stock aquaria (each species separately) for a week for acclimation. The acclimation period is crucial for our study, as it reduces the thermal sensitivity of the oxygen consumption rate and improves the heat tolerance of tested gammarids (Semsar-kazerouni and Verberk 2018). The stock aquaria were equipped with a system of constant water aeration and filtration. The animals were fed once a day, the fish with live gammarids of both species, the gammarids with frozen chironomid larvae. Moreover, the bottom of the aquaria with the gammarids was covered by plant detritus 
(additional food source) and gravel. Light conditions were natural (14:10-h light/dark), not supported by any artificial lights. To control water temperature $\left(20{ }^{\circ} \mathrm{C}\right)$ we used air conditioning and aquarium heaters with thermostats placed in each tank.

\section{Experimental setup and test procedure}

To check the effect of short and chronic predation risk, we tested 3 groups of gammarids (Online Resource Fig. S1). The first group was taken directly from the stock aquarium and not pre-exposed to the predation risk before the test. Therefore, the response of these individuals can be interpreted as a short-term reaction, occurring immediately after the appearance of a predator in the environment. The next two groups consisted of gammarids pre-exposed to predation risk for one or seven days before measurements, respectively, which allowed us to check the effect of sustained stress conditions on prey responses and to detect potential habituation and/or appearance of negative symptoms of chronic stress. Pre-exposure to the predator presence took place in 40-L tanks (water temperature: $20{ }^{\circ} \mathrm{C}$, as in the stock tanks) equipped with a net cage $(12 \times 14 \times 12 \mathrm{~cm})$ suspended in the water column. The experimental water temperature was suitable for both species, as confirmed by measurements at their collection sites, as well as an experimental test (van der Velde et al. 2009; Semsar-kazerouni and Verberk 2018). Gammarids (20 individuals per cage) were introduced to the cage, which protected them from perch predation (Supplement Fig. S1). The bottom of the cage was covered with gravel (11-15 $\mathrm{mm}$ in diameter), which could be used by gammarids as a shelter (Kobak et al. 2014, 2015), and detritus, similar to that in the stock tanks. During the pre-exposure, gammarids were fed daily, as during the acclimation. Gammarids in natural conditions occur at high density (Żytkowicz et al. 2008) and the effectiveness of their defence responses depends on the presence of conspecifics (Jermacz et al. 2017a). Therefore, both during the pre-exposure and during the test procedure gammarids were kept in groups. The individuals were not injured or damaged after the experiment, showing that antagonistic interactions among them were not common. Single fish were placed in the pre-exposure tanks 3 days before the gammarid introduction and fed every day (including the pre-exposure time) with the same gammarid species as that exposed in the cage (10 individuals of $D$. villosus or 20 individuals of $G$. jazdzewskii to account for the difference in gammarid size). Such a procedure guaranteed highly stressful conditions, resulting from the presence of cues emitted directly by predatory fish as well as of alarm cues from injured conspecifics. Simultaneously, we pre-exposed control individuals of each species for the same duration and under the same conditions, but in the absence of fish.

After the pre-exposure period, we placed a single-species group of 10 individuals randomly selected from the same cage in a tightly closed Karlsruhe bottle $(250 \mathrm{ml})$, filled with water containing the predator signal or control water. The pre-exposed gammarids were tested in the water taken from their pre-exposure tanks to avoid any new signals, masking potential habituation effects. Thus, we tested responses of animals exposed to a given signal for a specified time at the end of this exposure. This allowed us to check the effect of exposure duration, which was the primary goal of our study. In the case of gammarids not pre-exposed to the predator presence, the predator signal was prepared by incubation of a single fish for 3 days in a 40-L tank under the same conditions as those used during the pre-exposure of the other gammarid groups (Jermacz et al. 2017b). A similar fishless tank was used as a source of water for the control treatments with gammarids not pre-exposed to predators. We placed five pieces of gravel $(15 \pm 3.2 \mathrm{~mm})$ in the test bottle to provide shelters for the gammarids.

Altogether, we had 12 different experimental groups: 3 durations of pre-exposure to predators (none, 1 day, 7 days) $\times 2$ gammarid species $\times 2$ treatments (the predation cue present or absent during the test). The tests (7-21 replicates per each treatment) lasted for $35 \mathrm{~min}$, including an initial 5-min. period of acclimation. Gammarid oxygen consumption was measured during the subsequent $30 \mathrm{~min}$. of the test. After the test, gammarids were gently removed from the bottle, weighed to the nearest $0.1 \mathrm{mg}$ with Radwag AS 110/C/2 laboratory scales (Radom, Poland), homogenized (see below) and frozen $\left(-80^{\circ} \mathrm{C}\right)$ until the determination of physiological markers.

\section{Response variables}

To determine the effects of predation risk on gammarid metabolism rate, we measured their oxygen consumption corrected for weight and locomotory activity (time spent in movement). We estimated the strength of gammarid defence against oxidative stress by measuring the activity of the key antioxidant enzyme-catalase (CAT) (Monaghan et al. 2009). We also evaluated the heat shock protein 70 (Hsp 70) level, which is often increased in stress conditions (Sørensen et al. 2003), including predator presence (Slos and Stoks 2008). Moreover, to determine the level of oxidative stress (i.e. oxidative damage at the cellular level), we measured thiobarbituric acid reactive substances (TBARS) concentration, a commonly used marker of lipid peroxidation (Rice-Evans et al. 1991).

Oxygen concentration in the bottle was measured four times during the test: immediately after the acclimation period and after a subsequent 10, 20 and $30 \mathrm{~min}$. of 
exposure, using an optical oxygen sensor (FDO 925, WTW, Germany) connected with a multiparameter benchtop meter (inoLab Multi 9620 IDS, Germany). Gammarid respiration during the three 10-min. periods of exposure was calculated as the reduction in oxygen concentration in the bottle. Preliminary tests conducted in the absence of gammarids showed that the background reduction in oxygen concentration (caused, for example, by bacteria present in experimental water) was negligible and did not differ among the treatments. To control for the effect of gammarid activity (percentage of time spent in moving) on oxygen consumption, we simultaneously video-recorded their behaviour with an IP video camera (SNB-6004, Samsung, South Korea) placed vertically under the bottle. Then, we measured the percentage of time spent by gammarids in movement (average value of 10 individuals in the bottle) in three 10-min. periods corresponding to the above-mentioned measurements of oxygen concentration, using Noldus Ethovision XT 10.1 (Noldus Information Technology Inc., Leesburg, Netherlands) video analysis software. Dividing the measurement into three 10-min. periods allowed us to determine the duration of the acute gammarid response, as well as to check for any potential changes in this response with time.

Biochemical parameters (CAT activity, TBARS and Hsp70 concentration) were measured after a 35-min. exposure of gammarids to experimental conditions. Extracts for biochemical analyses were prepared from pooled specimens (samples of 250-500 mg) to obtain a sufficient amount of material. Live gammarids were homogenized in $6 \mathrm{ml}$ of potassium phosphate buffer at $\mathrm{pH} 7.4$ using a Potter homogenizer with a Teflon piston (200 rotations per minute) at $10{ }^{\circ} \mathrm{C}$. After centrifugation at $12,000 \mathrm{~g}$ for $10 \mathrm{~min}$ at $4{ }^{\circ} \mathrm{C}$, the supernatants were collected in Eppendorf tubes and stored at $-80{ }^{\circ} \mathrm{C}$ until analysis. Then, the samples were used for determination of CAT activity, as well as Hsp70 and TBARS concentration.

CAT activity was determined according to Bartosz (2008) by monitoring decomposition of $54 \mathrm{mM} \mathrm{H}_{2} \mathrm{O}_{2}$ in $50 \mathrm{mM}$ phosphate buffer (pH 7.0) in a total volume of $3 \mathrm{ml}$. For each sample, $20 \mu \mathrm{L}$ of homogenate was added to start the reaction and the decrease in absorbance during $3 \mathrm{~min}$. at an ambient temperature of $25{ }^{\circ} \mathrm{C}$ was measured at $240 \mathrm{~nm}$ with a spectrophotometer (Schimadzu UV-1800 spectrophotometer, Shimadzu Inc., Kyoto, Japan). The enzyme activity was expressed as $\mathrm{U} \mathrm{mg}$ protein $^{-1}$. The unit of CAT activity is defined as the reduction of $1 \mu \mathrm{mol}$ of the peroxide per minute. To relate the result to unit protein mass, the protein concentration was measured by the Folin-Phenol method described by Lowry et al. (1951). Bovine serum albumin (Sigma Chemical, Steinheim, Germany) was used as a standard.

The concentration of Hsp 70 was determined by a commercial sandwich Elisa kit from Biorbyt (UK catalogue number orb397140) according to the manufacturer's instruction. Colorimetric changes in the assay were detected using a multi-mode microplate reader Epoch 2 (BioTek Instruments, Inc., Winooski, UT, USA) and data were analysed using BioTek GEN 5 software. The sensitivity of the Hsp 70 kit was less than $80 \mathrm{pg} \mathrm{ml}^{-1}$.

TBARS concentration was determined according to RiceEvans, Diplock and Symons (1991). For each sample, $1 \mathrm{ml}$ of homogenate was added to $1 \mathrm{ml}$ of $15 \%$ TCA (w/v) and $0.37 \%$ (w/v) TBA in $25 \mathrm{mM} \mathrm{HCl}$. The samples were heated for $10 \mathrm{~min}$ in a boiling water bath to release MDA (the end product of lipid peroxidation) from proteins, then quickly cooled to avoid adsorption of MDA to insoluble proteins and immediately centrifuged for $5 \mathrm{~min}$ at $6500 \mathrm{~g}$. In parallel, two blank samples were prepared: one without TBA and the other without the homogenate. All samples were subjected to spectrophotometric analysis at $535 \mathrm{~nm}$. TBARS concentration was calculated using the molar extinction coefficient for MDA-TBA complex of $1.56 \times 10^{5} \mathrm{M}^{-1} \mathrm{~cm}^{-1}$ and expressed as $\mu$ mol g wet mass ${ }^{-1}$.

\section{Statistical analyses}

To analyse factors affecting oxygen consumption by gammarids (adjusted for their biomass and activity), we applied a General Linear Model (GLM) with predator presence, gammarid species and pre-exposure time as fixed categorical factors, as well as gammarid biomass and activity as continuous covariates. We log-transformed the variables for this analysis to linearize a potentially allometric relationship between biomass and metabolism. We carried out separate analyses for each 10-min. period of exposure (0-10, 11-20 and 21-30 min.). To analyse the effect of the predator presence, pre-exposure duration and species on biochemical markers (measured at the end of the test period), we applied a 3-way General Linear Model with predator presence, gammarid species and pre-exposure time as fixed factors.

As the pre-exposure time in itself could not explain gammarid behaviour adequately (they were pre-exposed to predation cues or control water), we included this variable in the models only in its interactions with the predation cue. This allowed us to check whether physiological traits of gammarids depended on their species and predation pressure (past or present), as well as whether their responses to predators differed between species and pre-exposure conditions. If needed, significant terms were further explored using sequential Bonferroni corrected LSD post hoc tests. We used SPSS Statistics 25.0 to conduct statistical analyses. 


\section{Results}

Respiration rate of gammarids (adjusted for their activity and biomass) during the first $10 \mathrm{~min}$. of the test depended on an interaction between gammarid species and predator presence (Table 1a). During this period, only D. villosus responded to the predation cue, doubling its oxygen consumption compared to the control treatment (Fig. 1a). During the period from 11 to $20 \mathrm{~min}$. of the test, oxygen consumption depended on gammarid species and predator presence, but not on the interaction between these factors (Table 1b). During this period, both species exhibited a higher oxygen consumption under predation cue than under control conditions and D. villosus showed a higher oxygen consumption than G. jazdzewskii (Fig. 1b). During the last period (21-30 min.) of the test we did not note any significant effects of predation risk or gammarid species on oxygen consumption of gammarids (Table 1c, Fig. 1c). Moreover, during the entire exposure period, gammarid respiration did not depend significantly on their pre-exposure conditions (Table 1), though a non-significant tendency to reduce the effect of predators on $D$. villosus pre-exposed to the predation cue for 7 days was visible (Fig. 1a, b).
The CAT activity as well as TBARS and Hsp70 concentrations depended on gammarid species, predator presence and pre-exposure time, as shown by significant interactions among these factors in the GLMs (Table 2a, b, c). After exposure to the predation cue, non-pre-exposed individuals of $G$. jazdzewskii exhibited about $150 \%$ higher CAT activity (Fig. 2), 270\% higher level of Hsp70 protein (Fig. 3) and almost $370 \%$ higher lipid peroxidation (Fig. 4) compared to the respective control treatment. Individuals of $G$. jazdzewskii pre-exposed to predation risk did not respond to the predation cue with changes in any of the above-mentioned biomarkers. Regardless of pre-exposure time, individuals of $D$. villosus exposed to the predation cue did not demonstrate any significant changes in any measured biomarkers compared to the respective control treatments.

\section{Discussion}

Predator presence induced significant modifications in the physiology of both gammarid species. However, the quality, strength and consequences of these responses differed between the tested species and depended on the time spent by gammarids in the presence of the predator. Under predation risk, both gammarid species significantly boosted their
Table 1 The General Linear Model to test the effect of the gammarid species, predator presence, pre-exposure time, gammarid mass and gammarid activity on the oxygen consumption during the three exposure periods $(1-10,11-20$ and $21-30 \mathrm{~min}$.)

\begin{tabular}{|c|c|c|c|c|c|c|c|}
\hline & Analysed period & Effect & & $d f$ & MS & $F$ & $P$ \\
\hline \multirow[t]{8}{*}{ A } & \multirow[t]{8}{*}{$1-10 \mathrm{~min}$} & \multirow[t]{5}{*}{ Experimental factors } & Species (S) & 1 & 0.059 & 9.200 & 0.003 \\
\hline & & & Predator $(\mathrm{P})$ & 1 & 0.071 & 10.976 & 0.001 \\
\hline & & & $\mathrm{S} \times \mathrm{P}$ & 1 & 0.070 & 10.943 & 0.001 \\
\hline & & & P x Pre-exposure & 4 & 0.010 & 1.615 & 0.174 \\
\hline & & & $\mathrm{S} \times \mathrm{P} \times$ Pre-Exposure & 4 & 0.005 & 0.744 & 0.563 \\
\hline & & \multirow[t]{2}{*}{ Covariates } & Mass & 1 & 0.010 & 1.479 & 0.226 \\
\hline & & & Activity & 1 & 0.001 & 0.161 & 0.689 \\
\hline & & Error & & 146 & 0.006 & & \\
\hline \multirow[t]{8}{*}{ B } & \multirow[t]{8}{*}{$11-20 \mathrm{~min}$} & \multirow[t]{5}{*}{ Experimental factors } & Species (S) & 1 & 0.087 & 8.573 & 0.004 \\
\hline & & & Predator $(\mathrm{P})$ & 1 & 0.082 & 8.066 & 0.005 \\
\hline & & & $\mathrm{S} \times \mathrm{P}$ & 1 & 0.016 & 1.568 & 0.213 \\
\hline & & & $\mathrm{P} \times$ Pre-exposure & 4 & 0.017 & 1.706 & 0.152 \\
\hline & & & $\mathrm{S} \times \mathrm{P} \times$ Pre-Exposure & 4 & 0.016 & 1.585 & 0.181 \\
\hline & & \multirow[t]{2}{*}{ Covariates } & Mass & 1 & 0.004 & 0.416 & 0.520 \\
\hline & & & Activity & 1 & 0.012 & 1.202 & 0.275 \\
\hline & & Error & & 142 & 0.01 & & \\
\hline \multirow[t]{8}{*}{$\mathrm{C}$} & \multirow[t]{8}{*}{$21-30 \mathrm{~min}$} & \multirow[t]{5}{*}{ Experimental factors } & Species (S) & 1 & 0.000 & 0.063 & 0.803 \\
\hline & & & Predator $(\mathrm{P})$ & 1 & 0.000 & 0.000 & 0.988 \\
\hline & & & $\mathrm{S} \times \mathrm{P}$ & 1 & 0.000 & 0.018 & 0.893 \\
\hline & & & $\mathrm{P} \times$ Pre-exposure & 4 & 0.004 & 0.566 & 0.687 \\
\hline & & & $\mathrm{S} \times \mathrm{P} \times$ Pre-Exposure & 4 & 0.008 & 1.091 & 0.363 \\
\hline & & \multirow[t]{2}{*}{ Covariates } & Mass & 1 & 0.048 & 6.347 & 0.013 \\
\hline & & & Activity & 1 & 0.017 & 2.258 & 0.135 \\
\hline & & Error & & 146 & 0.008 & & \\
\hline
\end{tabular}




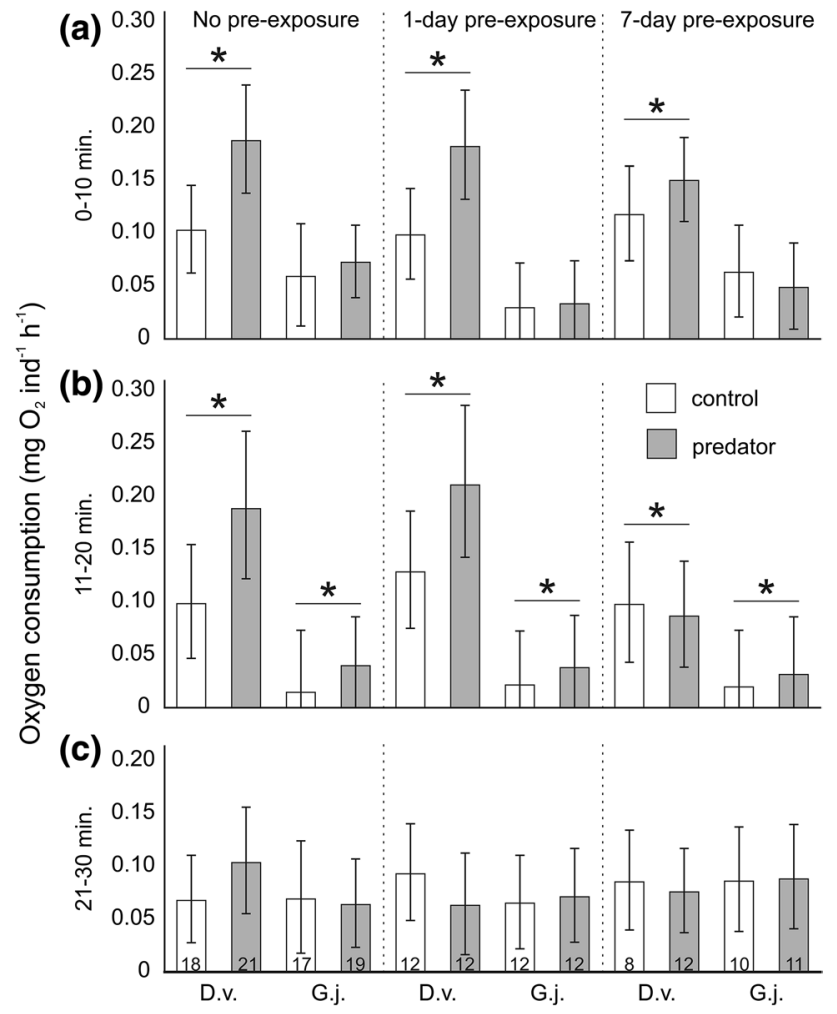

Fig. 1 Oxygen consumption by Dikerogammarus villosus (D.v.) and Gammarus jazdzewskii (G.j.) not pre-exposed, pre-exposed for 1 day or 7 days to the predation cue (grey bars) or control water (white bars) during consecutive periods of the test: (a) 0-10 min., (b) 11-20 min., (c) 21-30 min. The presented values are least square means (back-transformed after the analysis of log-transformed data) predicted by the General Linear Model for average gammarid biomass and activity during the respective test period. Asterisks indicate significantly higher or lower oxygen consumption rate by predatorstressed gammarids compared to corresponding control individuals. Error bars show $95 \%$ confidence intervals, numbers on the bars indicate sample sizes (the same for all panels)

oxygen consumption rates, independent of their activity and pre-exposure time. However, the timing of the increased oxygen consumption under predation risk was different for both species. Dikerogammarus villosus consumed more oxygen during the first and second period (0-20 min. after the start of the exposure) while G. jazdzewskii exhibited higher oxygen consumption only during the second period (10-20 min. after the start of the exposure). During the last period (20-30 min.), both prey species reduced their oxygen consumption to the level presented by non-stressed individuals. Increased oxygen consumption indicates increased metabolism, resulting in higher muscle efficiency. This is a common modification of prey physiology induced by predation risk (Rovero et al. 2000; Woodley and Peterson 2003; Slos and Stoks 2008). However, apart from its beneficial effects on prey survival, such a response also has negative physiological consequences for prey fitness due to the increased synthesis of ROS (De Block and Stoks 2008; Monaghan et al. 2009). The excess ROS influence key biological molecules, such as lipids, proteins and DNA (Hulbert et al. 2007; Monaghan et al. 2009), which impairs many aspects of organism functionality. For example, ROS may induce 10,000 DNA base modifications per cell per day (Ames 1991), generating negative phenotypic consequences (Falnes et al. 2007). ROS activity is also responsible for damage of lipids which are particularly important for membrane structure and function (Hulbert et al. 2007). Finally, ROS generate protein damage responsible for the decrease in muscle efficiency and reduction in defence capabilities (Janssens and Stoks 2014). Thus, the duration of a period of increased metabolic rate is limited and an organism is forced to mobilize its antioxidant defence to reduce the negative consequences of ROS activity. Therefore, in our study, gammarids exposed to predation cues exhibited only shorttime events of increased metabolic rate, which returned to its control value at the end of the measurement period.

An initial contact with the predator cue caused an increase in the activity of an enzymatic antioxidant (CAT) only in $G$. jazdzewskii. Previous studies demonstrated that long-term (chronic) predation risk can both increase (Slos et al. 2009) or reduce (Slos and Stoks 2008; Janssens and Stoks 2013) the activity of the antioxidant system. Here we demonstrated that the short-term (35 min) predation risk caused activation of antioxidant defence. However, in contrast to the previously observed effects of chronic predation risk (Slos and Stoks 2008), we observed no inhibition of the antioxidant defence caused by chronic exposure. The observed shortterm mobilization of an antioxidant system is likely to counteract negative effects of ROS released due to the increased metabolic rate and respiration. Nevertheless, the increased level of TBARS indicates that, despite the mobilization of antioxidant defence, G. jazdzewskii was unable to neutralize the higher productivity of ROS. Another physiological change in G. jazdzewskii during the initial contact with the predation cue was the increased concentration of heat shock proteins (Hsp70). These proteins are crucial for keeping the cell homeostasis under stress conditions induced by diverse internal and external factors, including predator presence (Slos and Stoks 2008; Hawlena and Schmitz 2010). However, their synthesis and maintenance are costly (Sørensen et al. 2003), and often positively correlated with growth reduction (Slos and Stoks 2008; Janssens and Stoks 2013).

We showed that in D. villosus, which maintained the higher metabolic rate for a longer period than the G. jazdzewskii, oxidative damage was not increased in the presence of the predation cue. This indicates its high tolerance to stress conditions in the presence of the predator, allowing it to save energetic resources, which could be spent on other functions, such as growth and/or reproduction. On the other hand, G. jazdzewskii had to expend additional resources 
Table 2 The 3-way General Linear Model to test the effect of the gammarid species, predator presence and preexposure time on the catalase activity (CAT) (A), heat shock protein (Hsp70) concentration (B) and concentration of thiobarbituric acid reactive substances (TBARS) (C)

\begin{tabular}{|c|c|c|c|c|c|c|}
\hline & Dependent variable & Effect & $d f$ & $M S$ & $F$ & $P$ \\
\hline \multirow[t]{6}{*}{ A } & \multirow[t]{6}{*}{ CAT activity } & Species (S) & 1 & $15,634.2$ & 9.5 & 0.003 \\
\hline & & Predator (P) & 1 & $48,641.6$ & 29.7 & $<0.001$ \\
\hline & & $\mathrm{S} \times \mathrm{P}$ & 1 & $35,257.5$ & 21.5 & $<0.001$ \\
\hline & & $\mathrm{P} \times$ pre-exposure & 4 & $33,645.9$ & 20.5 & $<0.001$ \\
\hline & & $\mathrm{S} \times \mathrm{P} \times$ pre-exposure & 4 & $47,673.8$ & 29.1 & $<0.001$ \\
\hline & & Error & 109 & 1638.7 & & \\
\hline \multirow[t]{6}{*}{ B } & \multirow[t]{6}{*}{ HSP 70 level } & Species (S) & 1 & $10,893,704.1$ & 54.8 & $<0.001$ \\
\hline & & Predator $(\mathrm{P})$ & 1 & $3,300,175.0$ & 16.6 & $<0.001$ \\
\hline & & $\mathrm{S} \times \mathrm{P}$ & 1 & $4,220,609.5$ & 21.2 & $<0.001$ \\
\hline & & $\mathrm{P} \times$ pre-exposure & 2 & $2,754,842.7$ & 13.9 & $<0.001$ \\
\hline & & $\mathrm{S} \times \mathrm{P} \times$ pre-exposure & 2 & $2,805,239.9$ & 14.1 & $<0.001$ \\
\hline & & Error & 70 & $198,657.4$ & & \\
\hline \multirow[t]{6}{*}{$\mathrm{C}$} & \multirow[t]{6}{*}{ TBARS level } & Species (S) & 1 & 231.6 & 13.8 & $<0.001$ \\
\hline & & Predator $(\mathrm{P})$ & 1 & 115.5 & 6.9 & 0.010 \\
\hline & & $\mathrm{S} \times \mathrm{P}$ & 1 & 157.8 & 9.4 & 0.003 \\
\hline & & $\mathrm{P} \times$ pre-exposure & 4 & 89.1 & 5.3 & 0.001 \\
\hline & & $\mathrm{S} \times \mathrm{P} \times$ pre-exposure & 4 & 176.0 & 10.5 & $<0.001$ \\
\hline & & Error & 110 & 16.8 & & \\
\hline
\end{tabular}

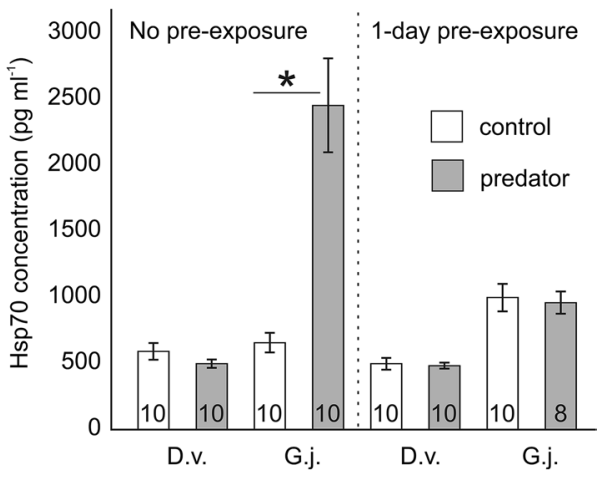

Fig. 3 Hsp 70 concentration in Dikerogammarus villosus (D.v.) and Gammarus jazdzewskii (G.j.) not pre-exposed or pre-exposed for 1 day to the predation cue (grey bars) or control water (white bars). Asterisks indicate significantly higher Hsp 70 concentration in predator-stressed gammarids compared to corresponding control individuals. Error bars are standard errors of the mean, numbers on the bars indicate sample sizes

undisturbed growth rate under predatory pressure, in contrast to the less armoured and more active related species (Jermacz and Kobak 2017).

We have demonstrated that the tested species bear different costs of their initial responses to the predation cue. One of the potential explanations of this difference is related to different defence strategies exhibited by each species. Compared to G. jazdzewskii, D. villosus is well armoured with an exoskeleton harder than that of other gammarids (Błońska et al. 2015) and exhibits a "sit-and-wait" strategy with an inclination to cling to complex hard substrata independently of the current level of predation risk (Kobak et al. 2014; 


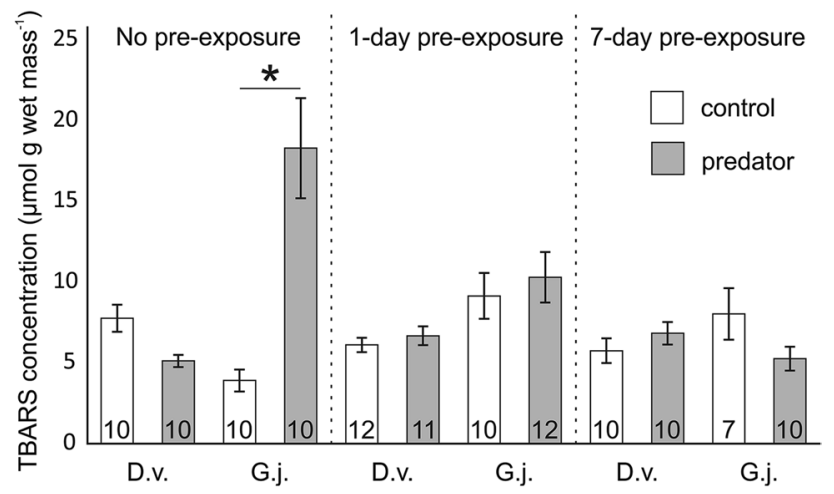

Fig. 4 TBARS concentration in Dikerogammarus villosus (D.v.) and Gammarus jazdzewskii (G.j.) not pre-exposed, pre-exposed for 1 day or 7 days to the predation cue (grey bars) or control water (white bars). Asterisks indicate significantly higher TBARS concentration in predator-stressed gammarids compared to corresponding control individuals. Error bars are standard errors of the mean, numbers on the bars indicate sample sizes

Jermacz et al. 2017a). Moreover, even immobilized individuals of $D$. villosus were selected by fish less often than G. jazdzewskii (Błońska et al. 2015), confirming the effectiveness of their non-inducible morphological anti-predator adaptations. Thus, many elements of $D$. villosus' defence strategy are not induced by predator presence. Accordingly, its physiological response is not as pronounced as that exhibited by species relying on their inducible defence mechanisms. On the other hand, G. jazdzewskii exposed to predation in a limited space has been experimentally demonstrated to have a lower survival rate than other gammarids, even in sheltered conditions (Kobak et al. 2014; Błońska et al. 2015, 2016; Schmidt-Drewello et al. 2016). Therefore, to reduce predation risk in natural conditions, G. jazdzewskii has to relocate immediately after the detection of a predator. When movement is the optimum way to avoid predators, G. jazdzewskii maximizes its muscle efficiency to increase response effectiveness despite the negative consequences of sustaining a higher metabolic rate. Nevertheless, further studies on a range of species differing in their anti-predator defence strategies are needed to confirm this hypothesized relationship.

Contrary to our prediction, only G. jazdzewskii exhibited the most pronounced response immediately after predator detection, while its reactions after 1 and 7 days of pre-exposure to predation risk were significantly reduced. Nevertheless, chronic predation risk was demonstrated to generate significant oxidative damage (Slos and Stoks 2008; Janssens and Stoks 2014) affecting prey defence abilities (Janssens and Stoks 2014). Here we showed that only G. jazdzews$k i i$ that activated its cellular defence at the initial contact with the predation cue, significantly reduced its long-term responses, despite the fact that its metabolic level was still higher than that of the control individuals. Such a situation indicates that under prolonged predation risk prey organisms were able to reconfigure their physiology to keep their increased metabolism simultaneously reducing costs related to the higher ROS synthesis. Another proof of the cost reduction during the long-term response to predators was shown by Van Dievel et al. (2016), who demonstrated the predator-induced growth reduction in damselfly larvae during a shorter exposure (3 days), while the impact of a longer contact with a predator was negligible. In contrast to $G$. jazdzewskii, $D$. villosus did not demonstrate any symptoms of physiological reconfiguration related to the prolonged exposure to predation risk. Nevertheless, its higher metabolism was also not followed by oxidative damage. Therefore, we assume that modifications in the physiology of this species were not necessary.

Understanding the role of non-consumptive predator effects, including adaptive abilities of prey organisms, is important as it may affect a prey population even more than direct predation (Preisser et al. 2005). We experimentally demonstrated that both prey species increased their metabolism rates under predation risk; however, their costs related to the cellular defence system were significantly different, pointing to a better adaptation of $D$. villosus to prolonged predator pressure. This might be one of the reasons for its high invasive success in many areas to which this species has recently expanded (Rewicz et al. 2014). On the other hand, we showed that G. jazdzewskii, suffering higher costs of the initial contact with the predation cue, was able to reconfigure its physiology during the prolonged exposure and reduce its negative effects on its organism.

Acknowledgements Our study was supported by the grant of the National Science Centre, Poland No. 2016/21/B/NZ8/00418. The experiments comply with the current laws of the country in which the experiments were performed. The authors declare no conflict of interest. We are grateful to Mrs Hazel Pearson for language corrections.

Author contribution statement $€ J$ conceived the ideas and designed the methodology. AN, HK and $€ J$ collected the data. $€ J$ and JK analysed the data. $€ \mathrm{~J}$ and JK led the writing of the manuscript, with contributions from AN and HK. All authors contributed critically to the drafts and gave final approval for publication.

\section{Compliance with ethical standards}

Ethical approval All applicable institutional and/or national guidelines for the care and use of animals were followed. The experiments conducted in this study have been approved by the Local Committee for Ethics in Animal Research in Bydgoszcz, Poland (statement no 35/2013 from 12 December 2013).

Open Access This article is licensed under a Creative Commons Attribution 4.0 International License, which permits use, sharing, adaptation, distribution and reproduction in any medium or format, as long as you give appropriate credit to the original author(s) and the source, 
provide a link to the Creative Commons licence, and indicate if changes were made. The images or other third party material in this article are included in the article's Creative Commons licence, unless indicated otherwise in a credit line to the material. If material is not included in the article's Creative Commons licence and your intended use is not permitted by statutory regulation or exceeds the permitted use, you will need to obtain permission directly from the copyright holder. To view a copy of this licence, visit http://creativecommons.org/licenses/by/4.0/.

\section{References}

Ames BN (1991) Endogenous oxidants as a cause of aging and cancer. In: Davies KJA (ed) Oxidation damage and repair: chemical, medical and biological aspects. Pergamon press, New York, pp $181-187$

Bartosz G (2008) Druga twarz tlenu: wolne rodniki w przyrodzie. Wydawnictwo Naukowe PWN, Warsaw

Beermann J, Boos K, Gutow L, Boersma M, Peralta AC (2018) Combined effects of predator cues and competition define habitat choice and food consumption of amphipod mesograzers. Oecologia 186:645-654. https://doi.org/10.1007/s00442-017-4056-4

Benard MF (2004) Predator-induced phenotypic plasticity in organisms with complex life histories. Annu Rev Ecol Evol Syst 35:651-673. https://doi.org/10.1146/annurev.ecolsys.35.02100 4.112426

Błońska D, Grabowska J, Kobak J, Jermacz Ł, Bącela-Spychalska K (2015) Feeding preferences of an invasive Ponto-Caspian goby for native and non-native gammarid prey. Freshw Biol 60:2187-2195. https://doi.org/10.1111/fwb.12647

Błońska D, Grabowska J, Kobak J, Rachalewski M, Bącela-Spychalska K (2016) Fish predation on sympatric and allopatric preya case study of Ponto-Caspian gobies, European bullhead and amphipods. Limnol Ecol Manag Inl Waters 61:1-6. https://doi. org/10.1016/j.limno.2016.06.003

Bollache L, Kaldonski N, Troussard J-P, Lagrue C, Rigaud T (2006) Spines and behaviour as defences against fish predators in an invasive freshwater amphipod. Anim Behav 72:627-633. https://doi. org/10.1016/j.anbehav.2005.11.020

Creel S, Christianson D, Liley S, Winnie JA (2007) Predation risk affects reproductive physiology and demography of elk. Science 315:960-960. https://doi.org/10.1126/science.1135918

Dalton CM, Flecker AS (2014) Metabolic stoichiometry and the ecology of fear in Trinidadian guppies: consequences for life histories and stream ecosystems. Oecologia 176:691-701. https://doi. org/10.1007/s00442-014-3084-6

De Block M, Stoks R (2008) Compensatory growth and oxidative stress in a damselfly. Proc R Soc B Biol Sci 275:781-785. https://doi. org/10.1098/rspb.2007.1515

Engel K, Tollrian R (2009) Inducible defences as key adaptations for the successful invasion of Daphnia lumholtzi in North America? Proc Biol Sci 276:1865-1873. https://doi.org/10.1098/ rspb.2008.1861

Falnes PØ, Klungland A, Alseth I (2007) Repair of methyl lesions in DNA and RNA by oxidative demethylation. Neuroscience 145:1222-1232. https://doi.org/10.1016/j.neuroscien ce. 2006.11 .018

Hawlena D, Schmitz OJ (2010) Physiological stress as a fundamental mechanism linking predation to ecosystem functioning. Am Nat 176:537-556. https://doi.org/10.1086/656495

Hawlena D, Kress H, Dufresne ER, Schmitz OJ (2011) Grasshoppers alter jumping biomechanics to enhance escape performance under chronic risk of spider predation. Funct Ecol 25:279-288. https:// doi.org/10.1111/j.1365-2435.2010.01767.x

Hulbert AJ, Pamplona R, Buffenstein R, Buttemer WA (2007) Life and death: Metabolic rate, membrane composition, and life span of animals. Physiol Rev 87:1175-1213. https://doi.org/10.1152/ physrev.00047.2006

Janssens L, Stoks R (2013) Predation risk causes oxidative damage in prey. Biol Lett 9:20130350. https://doi.org/10.1098/ rsbl.2013.0350

Janssens L, Stoks R (2014) Chronic predation risk reduces escape speed by increasing oxidative damage: a deadly cost of an adaptive antipredator response. PLoS ONE 9:e101273. https://doi. org/10.1371/journal.pone.0101273

Jermacz Ł, Kobak J (2017) Keep calm and don't stop growing: Nonconsumptive effects of a sympatric predator on two invasive Ponto-Caspian gammarids Dikerogammarus villosus and Pontogammarus robustoides. PLoS ONE 12:e0182481. https://doi. org/10.1371/journal.pone.0182481

Jermacz Ł, Andrzejczak J, Arczyńska E, Zielska J, Kobak J (2017a) An enemy of your enemy is your friend: Impact of predators on aggregation behavior of gammarids. Ethology 123:627-639. https ://doi.org/10.1111/eth.12635

Jermacz Ł, Dzierżyńska-Białończyk A, Kobak J (2017b) Predator diet, origin or both? Factors determining responses of omnivorous amphipods to predation cues. Hydrobiologia 785:173-184. https ://doi.org/10.1007/s10750-016-2917-1

Kobak J, Jermacz Ł, Płąchocki D (2014) Effectiveness of zebra mussels to act as shelters from fish predators differs between native and invasive amphipod prey. Aquat Ecol 48:397-408. https://doi. org/10.1007/s10452-014-9492-1

Kobak J, Jermacz Ł, Dzierżyńska-Białończyk A (2015) Substratum preferences of the invasive killer shrimp Dikerogammarus villosus. J Zool 297:66-76

Kottelat M, Freyhof J (2007) Handbook of European freshwater fishes. Publications Kottelat, Berlin

Lowry OH, Rosebrough NJ, Farr AL, Randall RJ (1951) Protein measurement with the Folin phenol reagent. J Biol Chem 193:265-275

McCauley SJ, Rowe L, Fortin M-J (2011) The deadly effects of "nonlethal" predators. Ecology 92:2043-2048. https://doi. org/10.1890/11-0455.1

Monaghan P, Metcalfe NB, Torres R (2009) Oxidative stress as a mediator of life history trade-offs: mechanisms, measurements and interpretation. Ecol Lett 12:75-92. https://doi.org/10.111 1/j.1461-0248.2008.01258.x

Naddafi R, Rudstam LG (2013) Predator-induced behavioural defences in two competitive invasive species: the zebra mussel and the quagga mussel. Anim Behav 86:1275-1284. https://doi. org/10.1016/j.anbehav.2013.09.032

Preisser EL, Bolnick DI, Benard MF (2005) Scared to death? The effects of intimidation and consumption in predator-prey interactions. Ecology 86:501-509. https://doi.org/10.1890/04-0719

Rewicz T, Grabowski M, MacNeil C, Bącela-Spychalska K (2014) The profile of a 'perfect' invader-the case of killer shrimp, Dikerogammarus villosus. Aquat Invasions 9:267-288

Rewicz T, Wattier R, Grabowski M, Rigaud T, Bącela-Spychalska K (2015) Out of the black sea: phylogeography of the invasive killer shrimp Dikerogammarus villosus across Europe. PLoS ONE 10:e0118121

Rice-Evans CA, Diplock AT, Symons MCR (1991) Techniques in free radical research. Elsevier Science Publishers BV, Amsterdam

Rovero F, Hughes RN, Chelazzi G (2000) When time is of the essence: choosing a currency for prey-handling costs. J Anim Ecol 69:683689. https://doi.org/10.1046/j.1365-2656.2000.00426.x

Rudolph K, Coleman CO, Mamos T, Grabowski M (2018) Description and post-glacial demography of Gammarus jazdzewskii sp. 
nov. (Crustacea: Amphipoda) from Central Europe. Syst Biodivers 16:587-603 doi. DOI: 10.1080/14772000.2018.1470118.

Sapolsky RM (2002) Endocrinology of the stress-response. In: Becker J, Breedlove S, Crews D, McCarthy M (eds) Behavioral endocrinology, 2nd edn. MIT Press, Cambridge, pp 409-450

Schmidt-Drewello A, Riss HW, Scharsack JP, Meyer EI (2016) Relative benefit of the invasive Echinogammarus berilloni (Catta, 1878) over native gammarids under fish predation (Gasterosteus aculeatus Linnaeus, 1758). Aquat Ecol 50:75-85. https://doi. org/10.1007/s10452-015-9555-y

Semsar-kazerouni M, Verberk WCEP (2018) It's about time: Linkages between heat tolerance, thermal acclimation and metabolic rate at different temporal scales in the freshwater amphipod Gammarus fossarum Koch, 1836. J Therm Biol 75:31-37. https://doi. org/10.1016/j.jtherbio.2018.04.016

Sheriff MJ, McMahon EK, Krebs CJ, Boonstra R (2015) Predatorinduced maternal stress and population demography in snowshoe hares: the more severe the risk, the longer the generational effect. J Zool 296:305-310. https://doi.org/10.1111/jzo.12249

Siepielski AM, Wang J, Prince G (2014) Nonconsumptive predatordriven mortality causes natural selection on prey. Evolution (N Y) 68:696-704. https://doi.org/10.1111/evo.12294

Slos S, Stoks R (2008) Predation risk induces stress proteins and reduces antioxidant defense. Funct Ecol 22:637-642. https://doi. org/10.1111/j.1365-2435.2008.01424.x

Slos S, De Meester L, Stoks R (2009) Food level and sex shape predator-induced physiological stress: immune defence and antioxidant defence. Oecologia 161:461-467. https://doi.org/10.1007/s0044 2-009-1401-2

Sørensen JG, Kristensen TN, Loeschcke V (2003) The evolutionary and ecological role of heat shock proteins. Ecol Lett 6:1025-1037. https://doi.org/10.1046/j.1461-0248.2003.00528.x

Strobbe F, McPeek MA, De Block M, Stoks R (2010) Survival selection imposed by predation on a physiological trait underlying escape speed. Funct Ecol 24:1306-1312. https://doi.org/10.111 $1 / \mathrm{j} .1365-2435.2010 .01752 . \mathrm{x}$
Thaler JS, McArt SH, Kaplan I (2012) Compensatory mechanisms for ameliorating the fundamental trade-off between predator avoidance and foraging. Proc Natl Acad Sci 109:12075-12080. https:// doi.org/10.1073/pnas.1208070109

van der Velde G, Leuven RSEW, Platvoet D, Bacela K, Huijbregts MAJ, Hendriks HWM, Kruijt D (2009) Environmental and morphological factors influencing predatory behaviour by invasive non-indigenous gammaridean species. Biol Invasions 11:20432054. https://doi.org/10.1007/s10530-009-9500-x

Van Dievel M, Janssens L, Stoks R (2016) Short- and long-term behavioural, physiological and stoichiometric responses to predation risk indicate chronic stress and compensatory mechanisms. Oecologia 181:347-357. https://doi.org/10.1007/s00442-015-3440-1

Werner EE, Anholt BR (1993) Ecological consequences of the trade-off between growth and mortality rates nediated by foraging activity. Am Nat 142:242-272

Werner EE, Peacor SD (2003) A review of trait-mediated indirect interactions in ecological communities. Ecology 84:1083-1100. https ://doi.org/10.1890/0012-9658(2003)084[1083:AROTII]2.0.CO;2

Woodley CM, Peterson MS (2003) Measuring responses to simulated predation threat using behavioral and physiological metrics: the role of aquatic vegetation. Oecologia 136:155-160. https://doi. org/10.1007/s00442-003-1236-1

Yoshida T, Jones LE, Ellner SP, Fussmann GF, Hairston NG (2003) Rapid evolution drives ecological dynamics in a predator-prey system. Nature 424:303-306. https://doi.org/10.1038/nature01767

Zanette LY, Clinchy M, Suraci JP (2014) Diagnosing predation risk effects on demography: can measuring physiology provide the means? Oecologia 176:637-651. https://doi.org/10.1007/s0044 2-014-3057-9

Żytkowicz J, Kobak J, Kakareko T, Kentzer A (2008) Species composition and distribution of invasive Ponto-Caspian amphipods in the off-channel microhabitats of a temperate, lowland dam reservoir. Int Rev Hydrobiol 93:62-72. https://doi.org/10.1002/iroh.20071 0966 